\title{
Multivalent Repression of Isoleucine-Valine Biosynthesis in Saccharomyces cerevisiae
}

\author{
P. T. MAGEE AND LYNNA M. HEREFORD \\ Department of Microbiology, Yale University School of Medicine, New Haven, Connecticut 06510
}

Received for publication 6 March 1969

\begin{abstract}
Regulation of the biosynthesis of four of the five enzymes of the isoleucine-valine pathway was studied in Saccharomyces cerevisiae. A method is described for limiting the growth of a leucine auxotroph by using valine as a competitor for the permease. Limitation for isoleucine and valine was accomplished by the use of peptides containing these amino acids conjugated with glycine as nutritional supplements for auxotrophs. The enzymes were repressed on synthetic medium containing isoleucine, valine, and leucine, as well as on broth supplemented with these amino acids. Limitation for any of the three branched-chain amino acids led to derepression of the isoleucine-valine biosynthetic pathway. Maximal derepression ranged from 3fold for threonine deaminase to approximately 10 -fold for acetohydroxyacid synthase. (Two of the enzymes, acetohydroxyacid synthase and dihydroxyacid dehydrase, may be controlled by a mechanism different from that regulating threonine deaminase.) Possible molecular mechanisms for multivalent repression are discussed.
\end{abstract}

The discovery, by Freundlich, Burns, and Umbarger (6), of multivalent repression in isoleucine-valine biosynthesis in Escherichia coli revealed a mechanism which regulates the levels of the enzymes of biosynthetic pathways leading to several products. This form of regulation, in which a deficiency of any one of the several products leads to derepression of the enzymes for the pathway, has also been shown to operate in the threonine-methionine pathway in $E$. coli $(2,4)$. It seems to be an alternative to the mode of regulation in which several enzymes, each repressed by one of the end products, catalyze a single step (13). So far, multivalent repression has been found only in these two pathways, and only in bacteria.

The regulation of the isoleucine-valine biosynthetic pathway in $E$. coli $\mathrm{K}-12$ is complex. There are two, or possibly three, operons involved $(2,6,14)$, and only one, that containing the enzymes catalyzing steps 1,4 , and 5 in Fig. 1 , is repressed multivalently. If the appropriate nutritional mutant is limited for the exogenous supply of isoleucine, valine, or leucine, these enzymes are coordinately derepressed 10 - to 20 -fold. Enzyme 2 on the other hand, is only derepressed by limitation for valine.

Because multivalent repression is a relative rarity even in bacterial systems, one might expect isoleucine-valine biosynthesis to be controlled differently in eucaryotes, whose regulatory mechanisms are in general less efficient. That differences between the two groups of organisms may occur is shown by the work of Gross (7), who demonstrated that leucine biosynthesis in Neurospora crassa is regulated by sequential induction, the product of the first enzyme of the pathway being the inducer for the next two enzymes. The two enzymes which were induced may have been coordinately induced but did not map adjacent one to the other.

In earlier reports $(1,10,11)$, we examined regulation of the activity of the first two enzymes concerned with isoleucine-valine biosynthesis in Saccharomyces cerevisiae. In this paper, we show that at least four of the five enzymes in the pathway are repressed multivalently by isoleucine, valine, and leucine, and that two of them may be depressed coordinately, at least over part of the range which we have been able to examine.

\section{MATERIALS AND METHODS}

Strains. M2 (trp iso-2), M6 (trp iso-1), M7 (trp iso-3), and M12 (trp iso-5) were isolated by $\mathrm{S}$. N. Kakar (8) and were obtained from D. Hawthorne. MD 13 (trp leu) is a leucine auxotroph isolated by mutagenesis with $N$-methyl- $N$-nitro- $N_{1}$-nitrosoguanidine from a segregant of a cross between M2 and NR 211-1a. The latter strain was obtained from $\mathrm{H}$. Hefner.

Media. Cells were grown on one of five media. Medium $\mathrm{Y}$ contained $10 \mathrm{~g}$ of Difco yeast extract, 10 $\mathrm{g}$ of Difco peptone, and $30 \mathrm{~g}$ of glucose per liter, and was supplemented with L-isoleucine, L-valine, and L-leucine, each at a concentration of $5 \times 10^{-3} \mathrm{M}$. Minimal medium (M) was the same as medium $G$ 


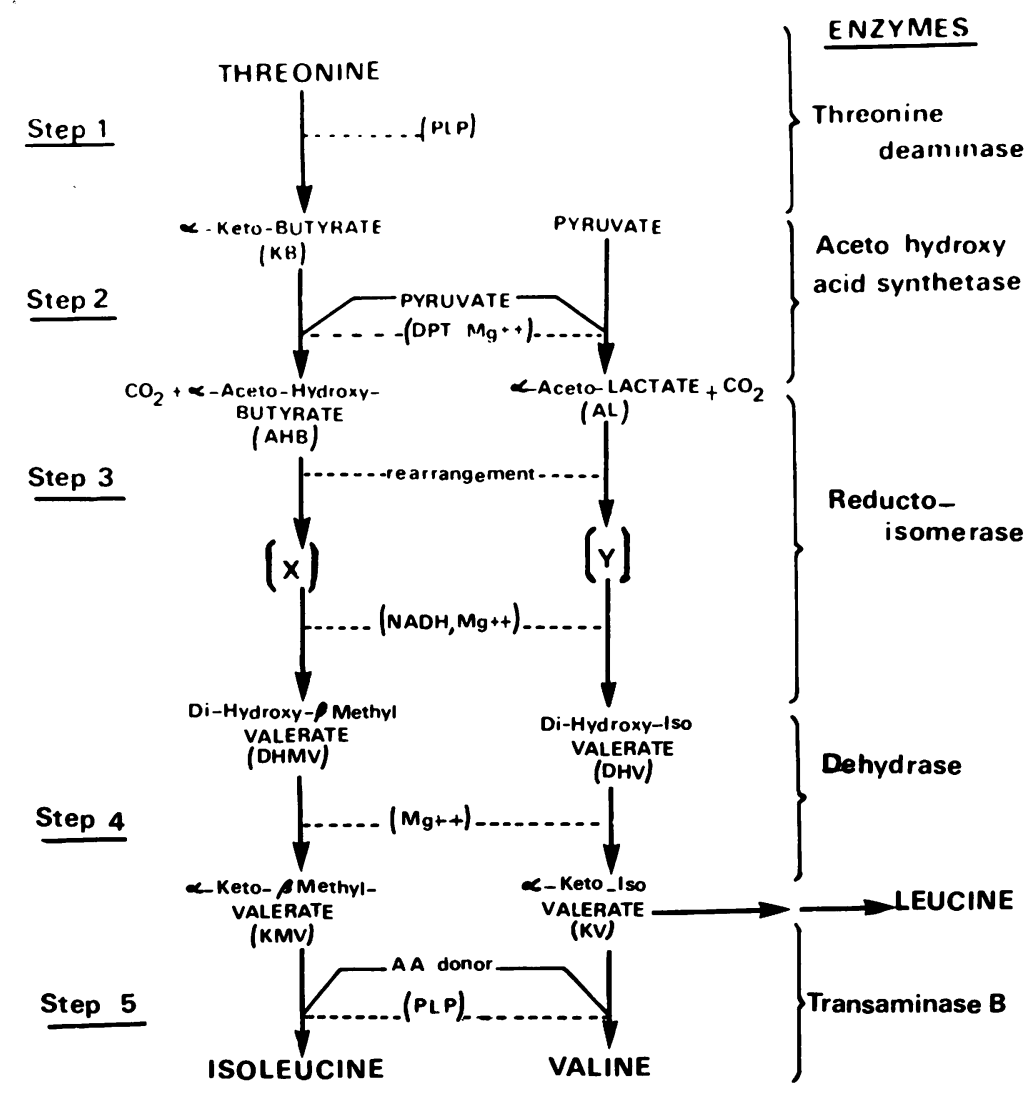

FIG. 1. Biosynthetic pathway for isoleucine and valine in Saccharomyces cerevisiae.

described previously (1) except that the $p \mathrm{H}$ was adjusted to 6.2 by the addition of $40 \mathrm{ml}$ of $1 \mathrm{M} \mathrm{K}_{2} \mathrm{HPO}_{4}$ per liter; $1 \mathrm{ml}$ of $0.5 \%$ L-tryptophan, $20 \mathrm{ml}$ of $0.1 \mathrm{M}$ $\mathrm{L}$-valine, and $5 \mathrm{ml}$ of $0.1 \mathrm{M} \mathrm{L}$-isoleucine were added per liter. Repressing medium (RM) was the same as medium $\mathrm{M}$ except that $50 \mathrm{ml}$ of $0.1 \mathrm{M}$ valine, $50 \mathrm{ml}$ of $0.1 \mathrm{M}$ isoleucine, and $100 \mathrm{ml}$ of $0.05 \mathrm{M} \mathrm{L}$-leucine were added per liter. Isoleucylglycine medium (IG) was the same as medium $\mathbf{M}$, except that the valine was increased to $50 \mathrm{ml} /$ liter, $270 \mathrm{mg}$ of $\mathrm{L}$-isoleucylglycine per liter was added, and isoleucine was omitted. Glycylvaline medium (GV) was medium $\mathrm{M}$ with 2.5 $\mathrm{ml}$ of valine per liter, $1 \mathrm{~g}$ of glycyl-DL-valine per liter, and $5 \mathrm{ml}$ of $0.1 \mathrm{M} \mathrm{L}$-isoleucine per liter. The latter two media were filter-sterilized.

Preparation of cells. For assay of the enzymes, the cells were shaken overnight in medium $Y$ at $30 \mathrm{C}$ and then were inoculated into $100 \mathrm{ml}$ of the appropriate medium in a 1-liter Erlenmeyer flask. The latter cultures were shaken overnight at $30 \mathrm{C}$ so that at least two divisions took place before harvesting. The inocula were adjusted so that the cell density at harvest would be between $10^{7}$ and $5 \times 10^{7} / \mathrm{ml}$. (Stationary phase is reached at about $2 \times 10^{8} / \mathrm{ml}$ in any medium except $Y$, where cells grow to a density of about $10^{9} / \mathrm{ml}$.)
The cultures were harvested by centrifugation and washed once with $40 \mathrm{ml}$ of $0.1 \mathrm{M}$ tris(hydroxymethyl)aminomethane (Tris)-hydrochloride $(p \mathrm{H}$ 7.7). The cells were then suspended in $5 \mathrm{ml}$ of buffer containing $25 \%$ glycerol, $0.5 \mathrm{~m}$ Tris-hydrochloride ( $\mathrm{pH}$ 7.7), $0.001 \mathrm{M}$ ethylenediaminetetraacetate, and $0.01 \mathrm{M}$ dithiothreitol. They were made permeable by the addition of $0.5 \mathrm{ml}$ of toluene followed by rapid mixing on a Vortex mixer for $30 \mathrm{sec}$ and incubation for 90 $\mathrm{sec}$ at $30 \mathrm{C}$. The cells were then centrifuged at 27,000 $\times g$ and were resuspended to give between 2 and 10 $\mathrm{mg}$ of protein per $\mathrm{ml}$, measured as described below. The wash after toluene treatment reduces the concentration of allosteric effectors which might affect the assays.

Enzyme assays. The assays for acetohydroxyacid synthase (AHA synthase) and threonine deaminase have been described previously $(10,11)$. AHA synthase was routinely assayed at $p \mathrm{H} 8.0$ to minimize contributions of the acetoin-forming system (10).

Dihydroxyacid dehydrase (DHA dehydrase) was assayed by a modification of the Friedmann-Haugen method. Cells which had been made permeable were incubated with $0.05 \mathrm{ml}$ of $0.05 \mathrm{M} \mathrm{MgSO}_{4}$ for $10 \mathrm{~min}$ at $30 \mathrm{C}$. The reaction was started by the addition of $0.05 \mathrm{ml}$ of a $10 \mathrm{mg} / \mathrm{ml}$ solution of DL-dihydroxyiso- 
valerate, sodium salt (prepared by Cyclo Chemical Co.), in $0.5 \mathrm{M}$ Tris-hydrochloride ( $\mathrm{pH}$ 7.7). After 20 min, the reaction was stopped by the addition of $0.25 \mathrm{ml}$ of $0.3 \%$ dinitrophenylhydrazine in $2 \mathrm{~N} \mathrm{HCl}$, and $10 \mathrm{~min}$ later $1.5 \mathrm{ml}$ of $1.5 \mathrm{~N} \mathrm{NaOH}$ was added. After another $10 \mathrm{~min}, 1.5 \mathrm{ml}$ of absolute ethyl alcohol was added. The tubes were mixed vigorously on a vortex mixer and centrifuged. The optical density (OD) of the reaction mixture was read at $520 \mathrm{~nm}$ on a Bausch \& Lomb Spectronic-20 colorimeter, and the quantity of ketoacid in each was determined from a standard curve prepared with pyruvate. A zero-time blank was always subtracted because the cells often contained some dinitrophenylhydrazine-positive material.

Reductoisomerase was assayed on a Gilford 2400 spectrophotometer in a reaction mixture containing (per $\mathrm{ml}$ ) $0.02 \mathrm{ml}$ of $0.05 \mathrm{M} \mathrm{MgSO}_{4}, 0.01 \mathrm{ml}$ of reduced nicotinamide adenine dinucleotide phosphate (NADPH; $10 \mathrm{mg} / \mathrm{ml}$ ), $0.03 \mathrm{ml}$ of $0.25 \mathrm{M}$ acetohydroxybutyrate (Reef Laboratories, Lafayette, Ind.), and

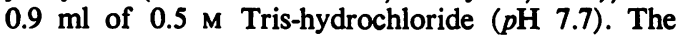
reaction was followed for $8 \mathrm{~min}$, and the $\Delta \mathrm{OD} /$ minute at $340 \mathrm{~nm}$ was calculated for the last $6 \mathrm{~min}$. The rate of oxidation of NADPH in a reaction mixture lacking substrate was subtacted from this value to give the true enzymatic rate. Assays of all four enzymes were always conducted in duplicate.

Protein assays. Samples of the cell preparations, diluted $1: 10$ or $1: 20$ in $1 \mathrm{M} \mathrm{NaOH}$, were boiled for 5 min and then centrifuged. The supernatant fluid was assayed by the method of Lowry et al. (9), with bovine serum albumin as a standard. Suitably diluted and boiled samples of the Tris-glycerol-DTT buffer were added to the standard curve, since DTT reacts to some extent in the Lowry assay.

\section{RESULTS}

Limitation of growth. Probably because of competition of the two amino acids for the same permease, it is very difficult to grow isoleucinevaline auxotrophs in a chemostat in a medium limiting for one or the other of these amino acids. Therefore, the cells were grown in batch culture, and peptides were used in place of the free amino acids to limit growth. For isoleucine, $0.27 \mathrm{mg}$ of $\mathrm{L}$ isoleucylglycine per $\mathrm{ml}$ was used. For valine, $1 \mathrm{mg}$ of DL-glycylvaline per $\mathrm{ml}$ served. Figure 2 shows that the generation times for a typical auxotroph were $12 \mathrm{hr}$ on isoleucylglycine and $7.5 \mathrm{hr}$ on glycylvaline. Medium M gave a generation time of $2.75 \mathrm{hr}$. To show that the cells are in fact limited by these peptides, one can restore the appropriate amino acid and decrease the generation time to the normal level. Thus, auxotrophs grown on these peptides as nutritional supplements could be expected to be derepressed for the biosynthetic enzymes.

Neither glycyleucine nor leucylglycine would serve as a source of leucine for a leucine auxotroph, so advantage was taken of the competition

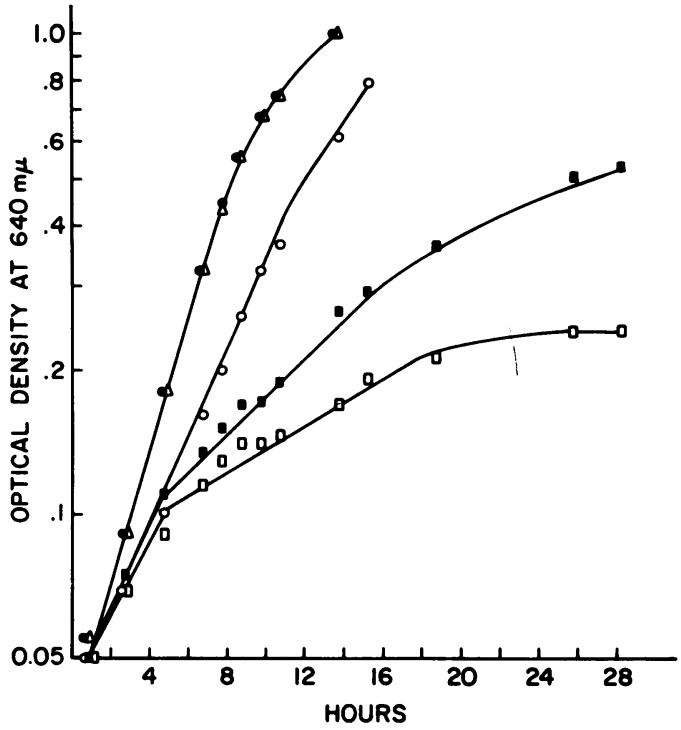

Fig. 2. Growth of M12 on isoleucyl glycine and glycylvaline. The cells were grown overnight on $M$ medium and then transferred to the appropriate medium. Growth was monitored by the increase in turbidity at $650 \mathrm{~nm}$. Symbols: $\triangle, M$ medium; $\mathbf{D}, G V$ medium; $\mathrm{O}, \mathrm{GV}$ medium $+5 \times 10^{-3}$ ML-valine; $\square, I G$ medium;, IG medium $+2.5 \times 10^{-3}$ ML-isoleucine.

of leucine and valine for the same permease. Figure 3 shows that the growth of MD13, a leucine auxotroph, was strongly inhibited by valine at concentrations of $1.5 \times 10^{-2}$ (generation time $=7 \mathrm{hr}$ ) and $2 \times 10^{-2} \mathrm{M}$ (generation time $=$ $9.25 \mathrm{hr}$ ) when leucine was present at $5 \times 10^{-4} \mathrm{M}$. Increasing the leucine to $10^{-2} \mathrm{M}$ restored normal growth (generation time $=3.25 \mathrm{hr}$ ). Both concentrations of valine were used to derepress this strain.

Derepression of isoleucine-valine biosynthetic enzymes. Table 1 shows the activities of the isoleucine-valine biosynthetic enzymes in various mutants grown on various media. Each value is the average of at least two experiments. It can be seen that derepression of four- to fivefold is possible for each of the enzymes except threonine deaminase. The latter increases at most threefold under conditions of isoleucine limitation and shows very little increase when valine is the limiting nutrient. Although all of these strains are presumably derived from the same parent, differing by a single mutation, they show rather different basal levels of the various enzymes. Furthermore, $M 7$ shows the highest specific activity of all of the enzymes on medium M, rather than on IG or GV medium. RM medium is less effective than $Y$ medium in repressing the enzymes in this strain, whereas the converse is true in the other strains. 


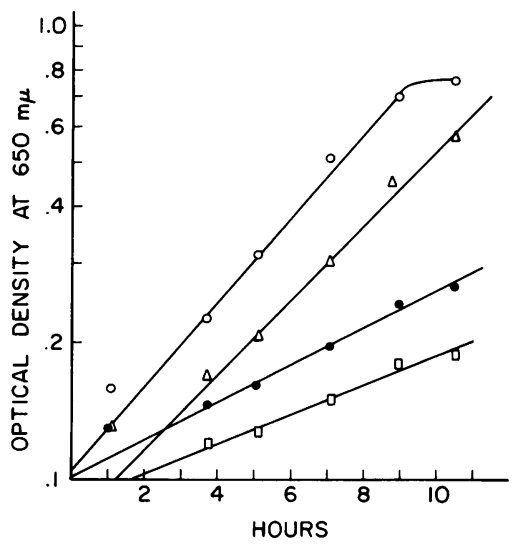

FIG. 3. Effect of added valine on the growth of MD13. The cells were grown overnight on minimal medium $+5 \times 10^{-4}$ ML-leucine and then transferred to medium containing $5 \times 10^{-4}$ ML-leucine (O), $5 \times$ $10^{-4}$ ML-leucine $+1.5 \times 10^{-2}$ ML-valine (O), $5 \times$ $10^{-4}$ ML-leucine $+2 \times 10^{-2}$ yL-valine $(\square)$, or $5 \times$ $10^{-3}$ ML-leucine $+2 \times 10^{-2}$ ML-valine $(\triangle)$.

Table 1 also shows the results of limitation for leucine in MD13. The levels of the AHA synthase in this strain are routinely lower than in any of the others, and the ratio of derepressed to repressed levels is greater (ninefold versus fivefold in M7). It can be seen that the enzymes involved in valine biosynthesis are in fact derepressed by limitation for leucine as well as for isoleucine and valine. Threonine deaminase shows about a twofold increase in the culture limited on leucine.

Relative levels of the various enzymes. Kakar and Wagner (8) showed that the genes iso-1, iso-2, iso-3, and iso-5 are not linked in S. cerevisiae. One would, therefore, expect that the derepression of the enzymes would not be coordinate. Figure 4, a plot of the specific activity under various growth conditions of threonine deaminase versus DHA dehydrase, shows that those enzymes are not coordinately controlled. Although a reasonably straight-line relationship can be drawn, the line does not extrapolate through the origin. Similar relationships can be shown for threonine deaminase versus AHA synthase and for reductoisomerase against any of the other three enzymes. In MD13, AHA synthase and DHA dehydrase, however, show an almost linear correlation (Fig. $5 A)$. Figure 5B demonstrates that the enzymes are not coordinately controlled over their entire range in M12; there is a region in which dehydrase increases without a concomitant increase in synthase. The fact that both curves extrapolate to a point close to the origin ( 0.07 units of dehydrase for MD13 and 0.013 units of synthase for M12) indicates that the synthesis of these enzymes may
TABLE 1. Levels of isoleucine and valine biosynthetic enzymes under various conditions ${ }^{a}$

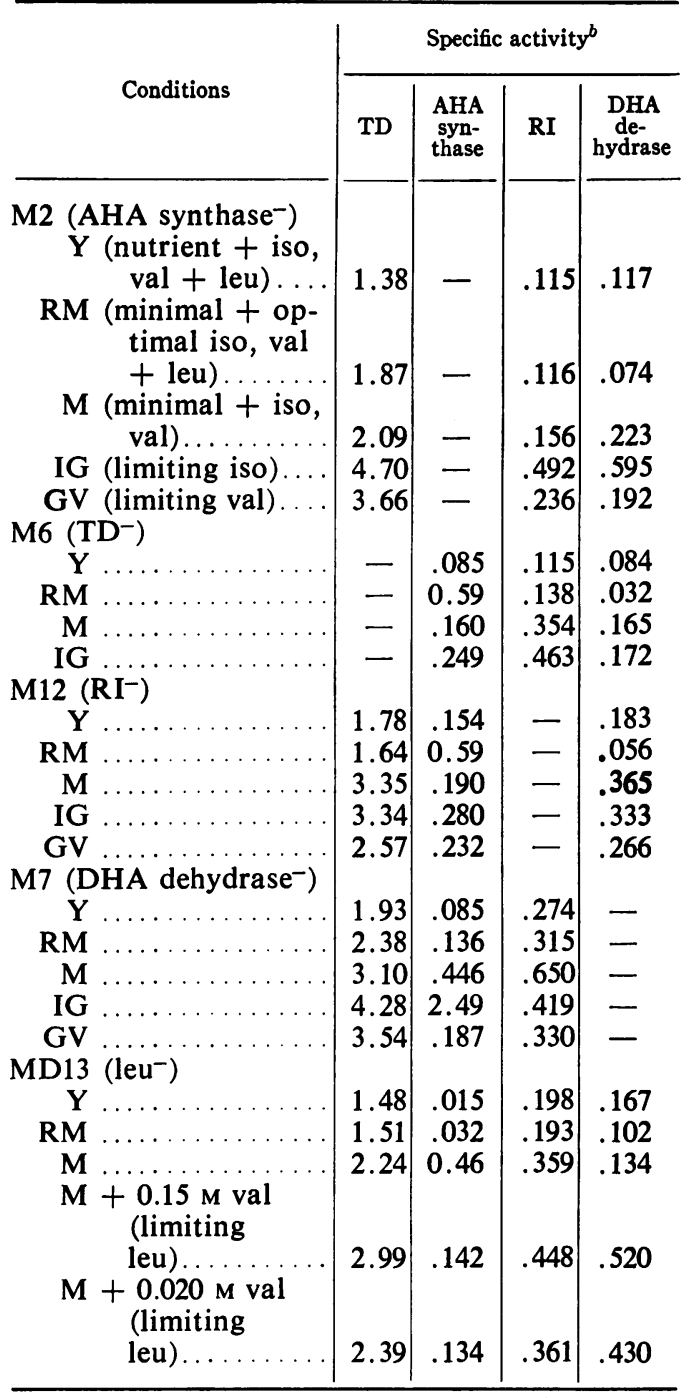

a Abbreviations: TD, threonine deaminase; AHA synthase, acetohydroxyacid synthase; RI, reductoisomerase; DHA dehydrase, dihydroxyacid dehydrase; iso, isoleucine; val, valine; leu, leucine; Y,RM, M, IG, and GV are media for which the compositions are given in Materials and Methods.

${ }^{b}$ Expressed as micromoles of product per $20 \mathrm{~min}$ per milligram of protein. All values are the average of two or more experiments.

be regulated by a mechanism which differs in some way from that for threonine deaminase. That this difference exists is indicated by the isolation of mutants derepressed for synthase and 


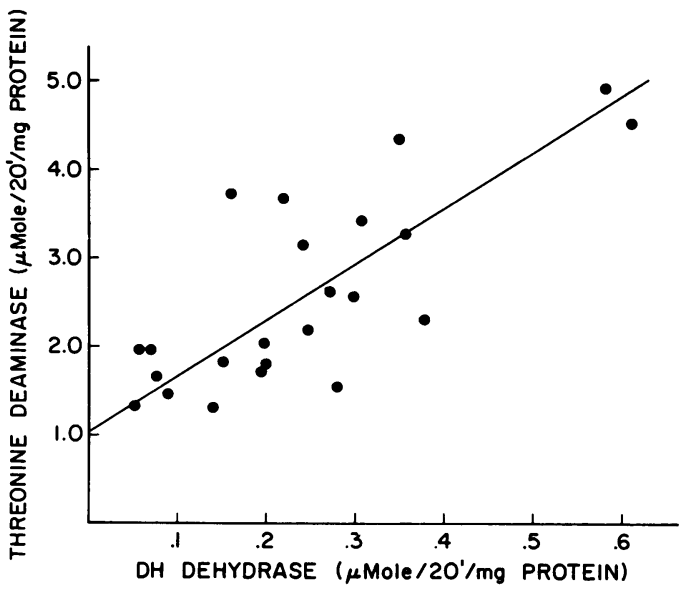

FIG. 4. Ratio of threonine deaminase to dihydroxyacid dehydrase (DH dehydrase) under various growth conditions in M2 and M12. The line is plotted by the least-square method. Intercept $=1.05 \pm 0.2$ units of threonine deaminase activity: correlation coefficient $=$ 0.79 .

dehydrase but not for threonine deaminase (P. T. Magee, in preparation).

\section{DISCUSSION}

Multivalent repression, not heretofore shown in eucaryotes, regulates the biosynthesis of isoleucine and valine in $S$. cerevisiae. Although the role of the vitamin pantothenic acid was not investigated in this study, it is clear that isoleucine, leucine, and valine are all necessary to repress the biosynthetic enzymes, and that limitation for any of these causes a derepression of these enzymes. This derepression may vary from 3-fold for threonine deaminase to 5- to 10-fold for AHA synthase. In bacteria, derepression for these enzymes may be as much as 50 -fold (2). Eucaryotes in general show a much smaller range of repressed to derepressed enzyme levels than bacteria.

The variation in the repression patterns of the various strains is worthy of comment. M7 seems totally derepressed on minimal medium, the values for AHA synthase and reductoisomerase being higher there than on any medium for any other strain. Furthermore, growth on limiting medium (IG or GV) gives lower specific activities for these two enzymes. RM medium also fails to depress these activities to a low level, although medium $\mathrm{Y}$ is somewhat more effective. Since M7 is an original isolate and not a segregant of the original isolate, it is quite possible that it carries a secondary mutation responsible for the elevated specific activities. It seems unlikely that this mutation is associated with anv nutritional leakiness

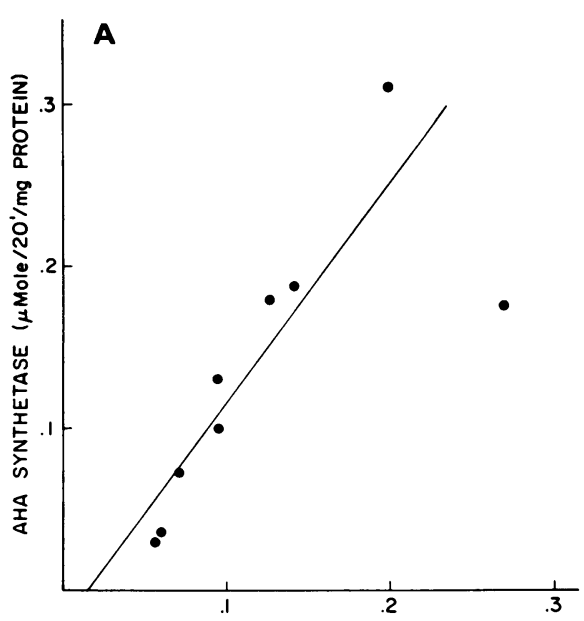

DH DEHYDRASE ( $\mu$ Mole/20//mg PROTEIN)

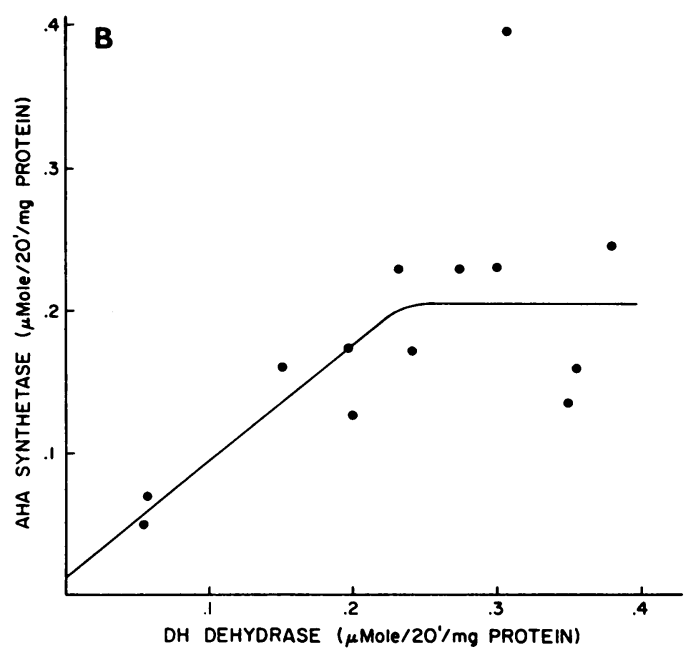

Fig. 5. Ratio of acetohydroxyacid synthase ( $A H A$ synthase) to dihydroxyacid dehydrase ( $D H$ dehydrase) under various growth conditions in various strains. Lines plotted by least-square method. (A) MD13. Intercept $=0.073 \pm 0.072$ units of dehydrase activity. Correlation coefficient $=0.69$. (B) M12. The line is fitted by eye. Intercept is 0.0125 units of $A H A$ synthase.

for another co-repressor, since M7 grows normally on $\mathrm{M}$ medium. The possibility that one of the products which accumulates in M7 (e.g., dihydroxyisovaleric acid) is an inducer, in analogy with the leucine pathway in $N$. crassa (7), seems to be eliminated by the fact that strains in which no dihydroxyacids can occur are normally derepressed on limiting medium.

IG medium seems in all cases to be more effec- 
tive than GV medium in derepressing the enzymes, but the generation time on IG medium is longer. The activity of AHA synthase is strictly dependent upon the cells being in log phase; the enzyme is destroyed in stationary-phase cells (Magee and de Robichon-Szulmajster, unpublished data).

The lack of coordination in the regulation of two of these four biosynthetic enzymes is to be expected, given the fact that they are not linked genetically. The question of whether there is a single regulatory mechanism acting upon all four, as is the case with the unlinked arginine genes in E. coli $(7 a)$, will remain open until regulatory mutants have been thoroughly studied. The fact that the plot of threonine deaminase versus synthase or dehydrase extrapolates to a basal level of about one rather than zero may indicate that the regulation of this enzyme, although physiologically similar, involves a molecular mechanism different from that for the other two.

Evidence to be reported elsewhere (Hartwell, McLaughlin, and Magee, in preparation) indicates that the isoleucyl-transfer ribonucleic acid (tRNA) synthase plays a part in multivalent repression in yeast, since strains with a temperature-sensitive isoleucyl-tRNA synthase show derepression for at least two of the enzymes in the pathway. Very similar results have been reported for strains of $E$. coli with a temperature-sensitive valyl-tRNA synthase. There is at present no evidence as to the role of leucyl-tRNA synthase in regulation of the isoleucine-valine pathway, although Printz and Gross (12) have shown that mutants of $N$. crassa with a lesion in the leucine-activating enzyme are not derepressed for the enzymes specific for the biosynthesis of leucine.

How the lack of any one of two or possibly three very complex molecules functions to turn on specific protein synthesis is presently far from clear. One possibility is that the system is analogous to the lac operon, with a single molecule serving as repressor. This molecule would have sites for each of the co-repressors; a lack of any one of the co-repressors would cause the molecule to lose its affinity for the operator and allow transcription of the appropriate genetic material. A second, closely related possibility is that the repressor has a single site for an inducer; this inducer would be any of the three types of uncharged tRNA. The site on the repressor would presumably have an affinity for some common sequence on the RNA molecules. Many other possibilities, some involving regulation at the translational level, can also be envisioned. To distinguish among these possibilities and to elucidate the molecular mechanism will require analysis of many sorts of mutants, among them derepressed strains and strains with lesions of various sorts in protein synthesis.

\section{ACKNOWLEDGMENT}

This investigation was supported by Public Health Service grant 1-R01-GM 15101 from the National Institute of Genera I Medical Sciences.

\section{LITERATURE GITED}

1. de Robichon-Szulmajster, H., and P. T. Magee. 1968. The regulation of isoleucine-valine biosynthesis in $S$. cerevisiae. I. Threonine deaminase. Eur. J. Biochem. 3:492-501.

2. Dwyer, S. B., and H. E. Umbarger. 1968. Isoleucine and valine metabolism of Escherichia coli. XVI. Pattern of multivalent repression in strain K-12. J. Bacteriol. 95:1680-1684.

3. Eidlic, L., and F. C. Neidhart. 1965. Role of valyl s-RNA synthetase in enzyme repression. Proc. Nat. Acad. Sci. U.S.A. 53:539-543.

4. Freundlich, M. 1963. Multivalent repression in the biosynthesis of threonine in Salmonella typhimurium and Escherichia coli. Biochem. Biophys. Res. Commun. 10:277-282.

5. Freundlich, M. 1967. Valyl-transfer RNA: role in the repression of the isoleucine-valine enzymes in $E$. coli. Science 157:823-825.

6. Freundlich, M., R. O. Burns, and H. E. Umbarger. 1962. Control of isoleucine, valine and leucine biosynthesis. I. Multivalent repression. Proc. Nat. Acad. Sci. U.S.A. 48: 1804-1808.

7. Gross, S. R. 1965. The regulation of synthesis of leucine biosynthetic enzymes in Neurospora. Proc. Nat. Acad. Sci. U.S.A. 54:1538-1546.

7a. Jacoby, G. A., and L. Gorini. 1969. A unitary account of the repression mechanism of arginine biosynthesis in Escherichia coli. I. The genetic evidence. J. Mol. Biol. 39:73-88.

8. Kakar, S. N., and R. P. Wagner. 1964. Genetic and biochemical analysis of isoleucine-valine mutants of yeast. Genetics 49:213-222.

9. Lowry, O. H., N. J. Rosebrough, A. L. Farr, and R. J. Randall. 1951. Protein measurement with the Folin phenol reagent. J. Biol. Chem. 193:265-275.

10. Magee, P. T., and H. de Robichon-Szulmajster. 1967. The regulation of isoleucine-valine biosynthesis in $S$. cerevisiae. II. Identification and characterization of mutants lacking the acetohydroxyacid synthetase. Eur. J. Biochem. 3:502506.

11. Magee, P. T., and H. de Robichon-Szulmajster. 1968. The regulation of isoleucine-valine biosynthesis in $S$. cerevisiae. III. Properties and regulation of the activity of acetohydroxy acid synthetase. Eur. J. Biochem. 3:507-511.

12. Printz, D. B., and S. R. Gross. 1967. An apparent relationship between mistranslation and an altered leucyl-t-RNA synthetase in a conditional lethal mutant of Neurospora crassa. Genetics 55:451-467.

13. Stadtman, E. R., G. N. Cohen, G. LeBras, and H. de Robichon-Szulmajster. 1961. Feed-back inhibition and repression of aspartokinase activity in Escherichia coli and Saccharomyces cerevisiae. J. Biol. Chem. 236:2033-2038.

14. Ramakrishnan, T., and E. A. Adelberg. 1965. Regulatory mechanisms in the biosynthesis of isoleucine and valine. II. Identification of two operator genes. J. Bacteriol. 89: 654-660. 